\title{
Pathological, immunohistochemical, and bacteriological findings in dogs infected with Brucella canis
}

\author{
Ji-Youl Jung ${ }^{1,4}$, Soon-Seek Yoon ${ }^{1}$, Seunghee Lee ${ }^{1}$, Jung-Won Park ${ }^{1}$, JinJu Lee ${ }^{2}$, Moon Her ${ }^{3}$, \\ ByungJae So ${ }^{1}$, Jae-Hoon Kim ${ }^{4, *}$
}

${ }^{1}$ Animal Disease Diagnostic Research Division, ${ }^{2}$ Bacterial Disease Research Division, and ${ }^{3}$ Research Planning \& Management Division, Animal and Plant Quarantine Agency, Gimcheon 39660, Republic of Korea

${ }^{4}$ College of Veterinary Medicine and Veterinary Medical Research Institute, Jeju National University, Jeju 63243, Republic of Korea

\begin{abstract}
This study describes pathological, immunohistochemical, and bacteriological findings in adult dogs and fetuses naturally infected with Brucella (B.) canis. A total of 42 dogs including 40 dogs and 2 aborted fetuses were examined. The most common gross lesions in infected dogs were swelling of lymph nodes and spleen. The testes showed marked swelling with multifocal to diffuse reddish discoloration. The most significant histopathological lesions were observed in the placenta. Placental trophoblasts were markedly hypertrophied due to the accumulation of intra-cellular gram-negative bacteria. Lymphocytic inflammation of varying severity was observed in the reproductive organs such as male testis, epididymis, and prostate gland and female uterus. Strong immunolabelling was observed in the cytoplasm of most trophoblasts in the placental tissues using immunohistochemistry. However, immunohistochemical staining did not demonstrate any organisms in other organs of dogs and fetuses. B. canis isolates were most frequently obtained from the whole blood $(82.5 \%)$ and superficial inguinal lymph node $(77.5 \%)$ in both sexes. In addition, the isolation rate was higher in male genital organs than in those of females. Hence, management of male dogs is most important because infected dogs can play a role as carriers.
\end{abstract}

Keywords: bacteriology; Brucella canis; immunohistochemistry; pathology

*Corresponding author

Jae-Hoon Kim

Veterinary Medical Research Institute, College of Veterinary Medicine, Jeju National University, 102 Jejudaehak-ro, Jeju 63243, Korea

Tel: +82-64-754-3387

Fax: +82-64-702-9920

E-mail: kimjhoon@jejunu.ac.kr

ORCID:

Ji-Youl Jung

https://orcid.org/0000-0002-5938-2029

Soon-Seek

Yoon https://orcid.org/0000-0003-0908-8785

Seunghee Lee

https://orcid.org/0000-0001-9436-9033

Jung-Won Park

https://orcid.org/0000-0002-2546-9732

Jinju Lee

https://orcid.org/0000-0002-6946-1812

Moon Her

https://orcid.org/0000-0002-6684-7170

ByungJae So

https://orcid.org/0000-0002-6125-6873

Jae-Hoon Kim

https://orcid.org/0000-0002-4410-9126

Conflict of Interest

The authors declare no conflicts of interest.

Received: September 16, 2019

Revise d: November 28, 2019

Accepted: December 2, 2019

\section{Introduction}

Canine brucellosis is considered one of the most common bacterial zoonotic infections worldwide and a cause of great economic loss in kennels [1-3]. General symptoms of canine brucellosis are not readily evident [4]. Dogs infected with Brucella are usually febrile. However, some dogs remain asymptomatic. Therefore, many infections are not diagnosed by routine history taking or physical examinations.

The classical signs of canine brucellosis are spontaneous abortion in a supposedly healthy pregnant bitch or failure to conceive. Late abortion occurs between 30 and 57 days of gestation, and higher frequency of abortion is observed between 45 and 55 days [5]. Aborted fetuses are usually partially autolyzed, and edema, congestion, and hemorrhage are presented in the subcutaneous abdominal region [2]. Prolonged, viscous, and serosanguinous vaginal discharge can last for 1-6 weeks after abortion [5].

Target organs of Brucella (B.) canis are androgen-dependent tissues such as the epididymis and prostate gland in stud dogs. Orchitis or epididymitis causes pain and swelling of the testis. Males may have scrotal dermatitis because of constant licking and secondary infection with nonhemolytic staphylococci. Chronic or prolonged infection in stud dogs eventually leads to unilateral or bilateral testicular atrophy [4].

The diagnosis of brucellosis is based on the isolation of the pathogen from whole blood, semen, vaginal secretions, urine, and lymphoid tissues $[4,6]$. Moreover, several serological tests are available. Another method for the detection of B. canis in tissues is immunohistochemistry (IHC) [2]. This method is sensitive and specific, and capable of demonstrating the distributions of bacterial organisms in the tissues with characteristic lesions.

Despite the fact that several studies have been published on canine brucel- 
losis, much information still remains to be clarified in the aspect of pathologic lesions and immunohistochemical findings of this disease. This study describes the pathological, immunohistochemical, and bacteriological findings in adult dogs and fetuses naturally infected with $B$. canis.

\section{Materials and Methods}

\section{Animals}

Five occurrences of canine brucellosis were observed in breeding kennels at different regions in Korea. All kennels had histories of repeated abortion and decreased fertility after new entry of dogs from other kennels. After making a diagnosis of canine brucellosis, all dogs in kennels were examined based on the screening test such as serological and bacteriological tests according to brucellosis control strategies in Korea. If the result of tests was positive, infected dogs were sacrificed. This experiment conducted in accordance with guidelines established by the Animal and Plant Quarantine Agency Animal Care and Use Committee (No. 2017352).

Among these animals, 42 dogs including 40 dogs aged 6 months to 10 years (29 females and 11 males) and 2 aborted fetuses were examined in this study.

\section{Gross and histopathological findings}

At necropsy, tissue samples were evaluated for the presence of gross lesions. Samples of lymph nodes (retropharyngeal, superficial inguinal), mammary gland, uterus, placenta, testis, epididymis, prostate gland, scrotum, liver, spleen, and kidney were collected from dogs, whereas samples of the lung, liver, spleen, and kidney were collected from fetuses. All collected samples were fixed in $10 \%$ phosphate-buffered formalin for $24 \mathrm{~h}$ and routinely processed. The processed tissues were embedded in paraffin and stained with hematoxylin and eosin for light microscopic examination. Gram staining was also performed to clarify the bacterial pathogens in tissue sections.

\section{IHC}

To detect B. canis, IHC was performed on replicated sections. The major organs were stained with polyclonal hyperimmune rabbit antiserum at a dilution of 1:500. The antiserum for IHC was produced by two rabbits after intravenous inoculation of $1 \times 10^{6}$ colony-forming units of live $B$. canis strain.

The tissue sections were stained with the Ventana Discovery XT research instrument and RedMap Detection System (Ventana Medical Systems, Inc., USA), and counterstained with hematoxylin. Tissue sections from an uninfected dog were used as negative controls.

\section{Bacterial culture and identification}

During necropsy, parts of the genital organs (female: uterus and mammary gland; male: testis, epididymis, and prostate gland), lymph nodes (superficial inguinal and retropharyngeal lymph nodes), liver, kidney, urine, and whole blood were collected aseptically for microbiologic analysis.

To isolate $B$. canis from whole blood, approximately 2-3 $\mathrm{mL}$ was collected using heparin as anticoagulant. Blood sample was centrifuged at $4^{\circ} \mathrm{C}$, at $3,000 \mathrm{rpm}$ for $30 \mathrm{~min}$. After separating plasma from whole blood, buffy coat was used for bacterial isolation. The buffy coat layer was inoculated in tryptose phosphate broth (BD Bioscience, USA) containing $5 \%$ fetal bovine serum (FBS; GIBCO, USA) and incubated at $37^{\circ} \mathrm{C}$ under aerobic conditions for 30 days. Every 7 days, the broth cultures were inoculated onto sheep blood agar (SBA) and incubated for 3-4 days at $37^{\circ} \mathrm{C}$. Suspected colonies were selected and purified by further cultivation on SBA for 3-4 days at $37^{\circ} \mathrm{C}$.

To isolate $B$. canis from tissues, specimens were macerated with sterile phosphate-buffered saline. Tissue homogenates were inoculated directly onto tryptic soy agar (BD Bioscience) supplemented with 5\% FBS and antibiotic mixtures $(25 \mathrm{U} / \mathrm{mL}$ bacitracin, $20 \mu \mathrm{g} / \mathrm{mL}$ vancomycin, $5 \mu \mathrm{g} / \mathrm{mL}$ nalidixic acid, $5 \mathrm{U} / \mathrm{mL}$ polymyxin $\mathrm{B}, 10 \mu \mathrm{g} / \mathrm{mL}$ cycloheximide, and $100 \mathrm{U} / \mathrm{mL}$ nystatin). Plates were incubated at $37^{\circ} \mathrm{C}$ for 5-10 days and examined daily for the presence of colonies. Colonies were selected, inoculated onto 5\% SBA for $2-$ 4 days at $37^{\circ} \mathrm{C}$.

For bacterial species identification, genomic DNA was extracted from the isolates using a QIAamp DNA mini kit (Qiagen, Germany) according to the manufacturer's protocol. The identification of the isolates was confirmed using the novel Bruce-ladder multiplex polymerase chain reaction assay [7].

\section{Results}

\section{Gross findings}

The most common gross lesions were observed in the lymph nodes and spleen. These organs showed variable degrees of swelling. The testes showed marked swelling with multifocal to diffuse reddish discoloration (Fig. 1A). In some male dogs, epididymal swelling and scrotal necrosis were observed. Non-pregnant female dogs did not show any specific gross lesions. However, an aborting bitch showed brownish vulvar discharge. Aborted fetuses were often partially autolyzed with a brown or greenish-gray placenta (Fig. 1B).

\section{Histopathological findings}

Collected tissues from 40 dogs and 2 fetuses were examined histologically under the microscope. We analyzed histopathological lesions according to three different aged dogs $(<2$ years, 2-6 years, and $\geq 6$ years) and fetus groups. Furthermore, histopathological lesions of genital organs in male and female dogs were also analyzed.

The prevalence of microscopic lesions in genital organs of female and male dogs is summarized in Table 1. Mild to severe lymphohistiocytic interstitial inflammation was pre- 

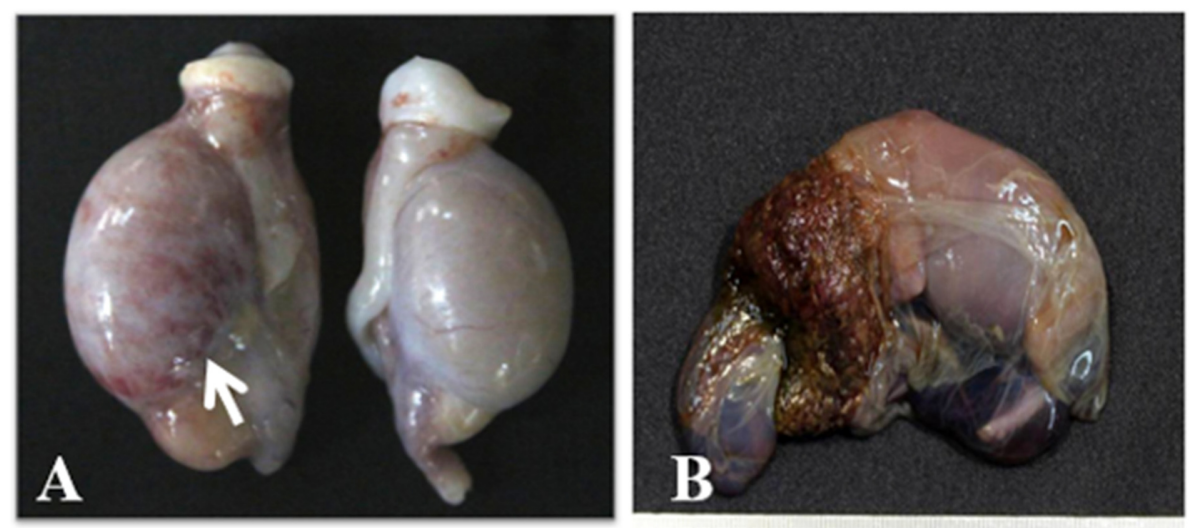

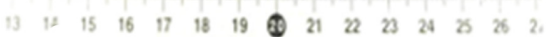

Fig. 1. (A) Testicular swelling with multifocal reddish discoloration (left, arrow). Normal testis (right). (B) An aborted fetus in the brown or greenish-gray placenta.

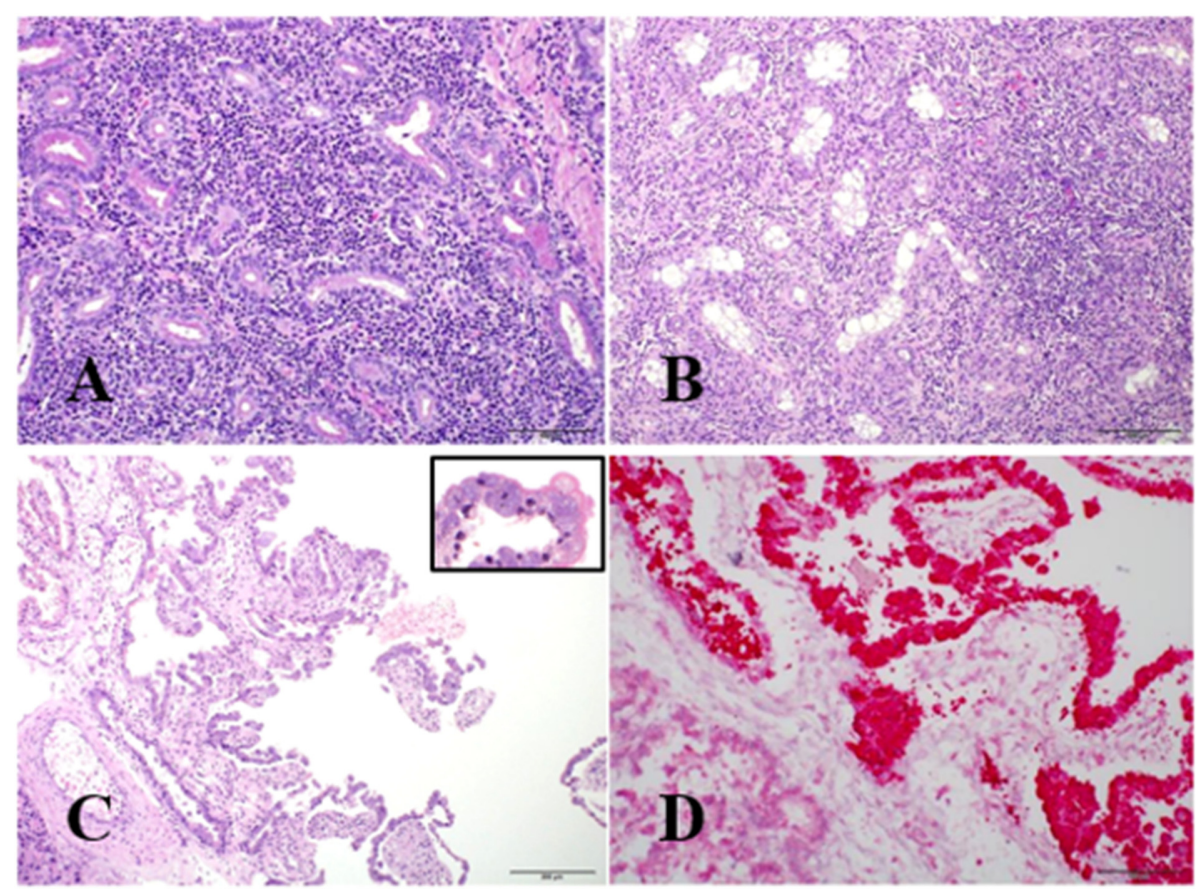

Fig. 2. (A) Interstitial lymphocytic infiltration and the irregular glandular structures in the prostate gland $(\mathrm{H} \& \mathrm{E} . \mathrm{bar}=100 \mu \mathrm{m})$. (B) Severe lymphohistiocytic orchitis with fibrosis and atrophy of seminiferous tubules in testis $(H \& E$. bar $=200 \mu \mathrm{m})$. (C) The chorioallantoic membrane lined by bacteria-laden hypertrophied trophoblasts (H\&E. bar $=200 \mu \mathrm{m}$; insert, a higher magnification of the trophoblasts, bar $=50 \mu \mathrm{m}$ ). (D) A strong positive red color reactions within the cytoplasm of trophoblast cells (immunohistochemistry, bar $=100 \mu \mathrm{m})$.

H\&E, hematoxylin and eosin.

sented in the $81.8 \%(9 / 11)$ prostate glands of male dogs (Fig. 2A). Scrotal dermatitis characterized by the infiltration of lymphocytes and neutrophils with epidermal ulceration or crust formation was observed in $72.7 \%(8 / 11)$ male dogs. Lymphocytic epididymitis and orchitis with testicular atrophy (Fig. 2B) were observed in 54.5\% (6/11) and in $36.4 \%$ (4/11) male dogs, respectively.

The mammary gland showed multifocal interstitial lymphocytic infiltration in $34.5 \%(10 / 29)$ female dogs. Multifo- cal-to-diffuse lymphocytic endometritis was observed in $31.0 \%(9 / 29)$ female dogs.

The most common microscopic lesion of non-reproductive organs was presented in the liver of both sexes. Multifocal neutrophilic or lymphocytic hepatitis was observed in $75.0 \%$ (30/40) dogs. Lymphoid tissues such as the lymph nodes and spleen usually showed follicular and white pulp hyperplasia with variable degree.

Most histopathologic lesions in male and female genital 
12 Ji-Youl Jung, Soon-Seek Yoon, Seunghee Lee, Jung-Won Park, JinJu Lee, Moon Her, ByungJae So, Jae-Hoon Kim

Table 1. Frequency of histopathological lesions in female and male organs according to age

\begin{tabular}{|c|c|c|c|c|c|c|c|}
\hline \multirow[b]{2}{*}{ Histological lesions } & \multicolumn{2}{|c|}{$<2 \mathrm{yr}$} & \multicolumn{2}{|c|}{$2-6 \mathrm{yr}$} & \multicolumn{2}{|c|}{$\geq 6 \mathrm{yr}$} & \multirow[b]{2}{*}{ Total } \\
\hline & $\begin{array}{c}\text { Male } \\
(\mathrm{n}=0)\end{array}$ & $\begin{array}{l}\text { Female } \\
(\mathrm{n}=7)\end{array}$ & $\begin{array}{l}\text { Male } \\
(\mathrm{n}=7)\end{array}$ & $\begin{array}{l}\text { Female } \\
(\mathrm{n}=13)\end{array}$ & $\begin{array}{c}\text { Male } \\
(n=4)\end{array}$ & $\begin{array}{l}\text { Female } \\
(\mathrm{n}=9)\end{array}$ & \\
\hline Orchitis & 0.0 & - & 14.3 & - & 75.0 & - & 36.4 \\
\hline Epididymitis & 0.0 & - & 42.9 & - & 75.0 & - & 54.5 \\
\hline Prostatitis & 0.0 & - & 85.7 & - & 75.0 & - & 81.8 \\
\hline Scrotal dermatitis & 0.0 & - & 71.4 & - & 75.0 & - & 72.7 \\
\hline Lymphocytic mastitis & - & 42.9 & - & 46.2 & - & 11.1 & 34.5 \\
\hline Lymphocytic endometritis & - & 28.6 & - & 53.8 & - & 0.0 & 31.0 \\
\hline Hepatitis & 0.0 & 71.4 & 85.7 & 69.2 & 75.0 & 77.8 & 75.0 \\
\hline Nephritis & 0.0 & 42.9 & 42.9 & 61.5 & 25.0 & 55.6 & 50.0 \\
\hline Follicular hyperplasia & 0.0 & 57.1 & 57.1 & 46.2 & 25.0 & 44.4 & 47.5 \\
\hline White pulp hyperplasia & 0.0 & 71.4 & 0.0 & 23.1 & 0.0 & 66.7 & 35.0 \\
\hline Uveitis & 0.0 & 0.0 & 14.3 & 7.7 & 0.0 & 0.0 & 5.0 \\
\hline
\end{tabular}

Values are presented as number (\%).

Table 2. Bacterial isolation rates of various samples in B. canis infected dogs (except aborted fetuses)

\begin{tabular}{|c|c|c|c|c|c|c|}
\hline \multirow[b]{2}{*}{ Samples } & \multicolumn{2}{|c|}{ Female } & \multicolumn{2}{|c|}{ Male } & \multicolumn{2}{|c|}{ Total } \\
\hline & No. of tested & $\begin{array}{c}\text { No. of isolates } \\
(\%)\end{array}$ & No. of tested & $\begin{array}{c}\text { No. of isolates } \\
(\%)\end{array}$ & No. of tested & $\begin{array}{c}\text { No. of isolates } \\
(\%)\end{array}$ \\
\hline Blood & 29 & $25(86.2)$ & 11 & $8(72.7)$ & 40 & $33(82.5)$ \\
\hline Superficial inguinal lymph node & 29 & $23(79.3)$ & 11 & $8(72.7)$ & 40 & $31(77.5)$ \\
\hline Spleen & 29 & $20(69.0)$ & 11 & $7(63.6)$ & 40 & $27(67.5)$ \\
\hline Retropharyngeal lymph node & 29 & $17(58.6)$ & 11 & $5(45.5)$ & 40 & $22(55.0)$ \\
\hline Liver & 29 & $14(48.3)$ & 11 & $5(45.5)$ & 40 & $19(47.5)$ \\
\hline Lung & 29 & $13(44.8)$ & 11 & $4(36.4)$ & 40 & $17(42.5)$ \\
\hline Kidney & 29 & $9(31.0)$ & 11 & $2(18.2)$ & 40 & $11(27.5)$ \\
\hline Urine & $24^{*}$ & $4(16.7)$ & 11 & $3(27.3)$ & 35 & $7(20.0)$ \\
\hline Uterus & 29 & $10(34.5)$ & & & 29 & $10(34.5)$ \\
\hline Prostate gland & & & 11 & $6(54.5)$ & 11 & $6(54.5)$ \\
\hline Epididymis & & & 11 & $5(45.5)$ & 11 & $5(45.5)$ \\
\hline Testis & & & 11 & $2(18.2)$ & 11 & $2(18.2)$ \\
\hline
\end{tabular}

*24 out of 29 samples examined.

organs were more frequently observed in aged dogs (over 2 years). However, there was no close relation between histopathological lesions in non-reproductive organs and dog's age.

Mild bronchopneumonia and suppurative hepatitis were existed in two aborted fetuses. Placental trophoblasts were markedly hypertrophied due to the accumulation of intra-cellular bacteria (Fig. 2C). These bacteria were confirmed as gram-negative coccobacilli using gram staining.

\section{IHC}

Strong red-colored immunolabelling was observed in the cytoplasm of most trophoblasts in the placental tissues (Fig. 2D). However, IHC did not demonstrate any organisms in the lesions of other organs of dogs and fetuses.

\section{Bacterial culture}

To examine bacterial isolation rates in various organs, genital and internal organs were obtained aseptically at necropsy. Bacteriological results are summarized in Table 2.

All dogs had positive results in bacterial culture at least one sample examined.

Bacterial isolates were most frequently obtained from the whole blood and frequent from the superficial inguinal lymph node and spleen in both sexes. In detail, bacterial isolates in female dogs were frequently obtained from the blood $(86.2 \% ; 25 / 29)$, superficial inguinal lymph node $(79.3 \% ; 23 /$ $29)$, and spleen $(69.0 \%$; 20/29). In male dogs, B. canis was most highly isolated from whole blood and superficial inguinal lymph node with same level $(72.7 \% ; 8 / 11)$, and spleen $(63.6 \% ; 7 / 11)$. Moreover, genital organs such as prostate gland $(54.5 \% ; 6 / 11)$ and epididymis $(45.5 \% ; 5 / 11)$ had higher 
frequency of bacterial isolations.

In the two aborted fetuses, $B$. canis isolates were recovered in tissues including the lung, spleen, liver, kidney, and placenta.

\section{Discussion}

This paper describes a comprehensive pathological, immunohistochemical, and bacteriological evaluation between adult dogs and fetuses naturally infected with $B$. canis.

The specific clinical signs of canine brucellosis are reproductive failure and infertility. All kennels in this study had histories of repeated abortion and decreased fertility. Owners requested samples related to abortion because they wanted to know the cause of reproductive problem. After the diagnosis of $B$. canis abortion, all dogs in five kennels were tested, and infected dogs were euthanized according to brucellosis control strategies in Korea. Although all dogs in this study were infected by $B$. canis, all dogs did not show typical gross lesions of canine brucellosis. They might have been euthanized before clinical signs were fully developed. Most prominent lesions were focused in the placentas characterized by hypertrophic trophoblasts with numerous intra-cellular bacterial colonies.

In bovines, trophoblasts are thought to be the primary target cell for invasion and multiplication of B. abortus in the placenta because of the presence of erythritol, or hormone synthesis by trophoblast cells [8]. Erythritol is a preferred nutrient and growth stimulant for Brucella species [9]. B. canis is also sensitive to erythritol. Therefore, in this study, intra-cellular B. canis was mainly observed at the hypertrophic trophoblasts of the placenta.

The most common gross lesions in this study were lymphadenomegaly and splenomegaly in both sexes and testicular degeneration and ulcerative scrotal dermatitis in males, in accordance with previous reports $[4,10]$. However, there were no specific gross lesions in non-pregnant females except one aborting bitch showing brownish vulvar discharge.

In the present study, lymphocytic or neutrophilic inflammations were observed in most internal organs of infected dogs. All genital organs such as testis, epididymis, prostate gland, mammary gland, and uterus showed multifocal to diffuse lymphocytic inflammation. Some dogs showed the swelling of lymph node and histopathologic lesions of lymphoid follicular hyperplasia were observed in 47.5\% (19/40) dogs. Swelling of lymph node is the result of diffuse lymphoreticular hyperplasia [11]. In chronic cases, the spleen is filled with plasma cells and macrophages containing phagocytized bacteria. Mild lymphocytic interstitial nephritis also noted in dogs with B. canis infection [11]. About 50.0\% (20/ 40) dogs had renal lesions of characteristic lymphocytic interstitial nephritis with variable degree. In accordance with a previous study [2], neutrophilic or lymphocytic hepatitis was also frequently observed in infected dogs.

Comparing with young dogs, old dogs may have increas- ing chance to antigenic stimuli. Therefore, various inflammatory processes are more popular in old dogs than in young dogs. We analyzed the pathological lesions in organs according to three different age groups $(<2$ years, $2-6$ years, and $\geq 6$ years). However, we could not find any relationships between dog's age and the severity of lesions in non-reproductive organs.

Moreover, most inflammation in animal organs can be induced by the injury or the infections including virus, bacteria, fungus, and others. However, we did not perform other etiological examinations except $B$. canis because all dogs used in this study were already confirmed to be infected with $B$. canis. They only showed the reproductive problem. Although the pathological lesions of internal organs might be associated with $B$. canis infection regardless of age, more in-depth studies are needed to clarify the association between lymphocytic inflammation in various organs and $B$. canis infection.

We applied IHC to identify $B$. canis antigens in tissues using hyperimmune rabbit antiserum. There were several reports on the immunohistochemical results of $B$. canis infection using antiserum. Hofer et al. [12] demonstrated B. canis antigens in placenta and aborted fetal lungs using IHC method. Gyuranecz et al. [2] reported immunolabelling in an aborted placenta and in a few macrophages and multinucleated giant cells in the tonsils and lymph nodes of adult dogs. In this study, the only but very strong positive result was obtained from an aborted placenta. The abortion of dogs in this study could be clearly attributed to B. canis infection, because large amounts antigens were detected in placenta. Unfortunately, we could not find any positive reactions for IHC in other internal organs of dogs and fetuses.

B. canis isolates were recovered in various tissues from 40 adult dogs and 2 aborted fetuses. The bacterial isolation was most frequent in blood samples. Whole blood is considered as the best choice of sample for the isolation of $B$. canis because of the characteristic prolonged bacteremia of canine brucellosis. Moreover, blood is the easiest material for aseptic collection and easy handling without sacrifice of dog [13]. In previous studies, the best organs for bacterial isolation were the lymph nodes, prostate, spleen, and sometimes the liver and testes at necropsy [11]. The overall positive results of bacterial culture in this study were similar to those in previous reports. In bitches, the uterus, placenta, and vaginal or uterine fluids were the most preferable tissues for bacterial isolation [2]. Isolation rates of B. canis are higher in lymphoid tissues such as lymph node and spleen than female and male genital organs in this study. This phenomenon might be closely related with long persistence of $B$. canis within mononuclear phagocytes [4]. B. canis were isolated more frequently in male genital organs including prostate gland and epididymis than in female uterus. However, B. canis in this study was also isolated from $18.2 \%(2 / 11)$ testis with low frequency. Histopathologically, B. canis infected testis showed severe lymphohistiocytic orchitis with fibrosis and atrophy of seminiferous tubules. These testicular damages may affect sperm production as well as sperm abnormalities such as 
immature sperm, deformed acrosomes, swollen midpieces, coiled tails $[3,11]$.

In conclusion, although the clinical signs were not typical in the Brucella-infected dogs, the bacterial isolation rates were relatively high, and many dogs showed histopathological lesions in genital organs associated with Brucella infection. It is important that the periodic monitoring system in kennels especially in male dogs should be confirmed for elimination of infected dogs and prevention of further disease transmission.

\section{Acknowledgments}

This work was supported financially by a grant (B1543069-2015-16-02) from the Animal and Plant Quarantine Agency, Republic of Korea.

\section{References}

1. Carmichael LE. Brucella canis. In: Nielsen KH, Duncan JR (eds.). Animal Brucellosis. pp. 336-350, CRC Press, Boca Raton, 1990.

2. Gyuranecz M, Szeredi L, Rónai Z, Dénes B, Dencso L, Dán , Pálmai N, Hauser Z, Lami E, Makrai L, Erdélyi K, Jánosi S. Detection of Brucella canis-induced reproductive diseases in a kennel. J Vet Diagn Invest 2011;23:143-147.

3. Wanke MM. Canine brucellosis. Anim Reprod Sci 2004;8283:195-207.

4. Rodriguez Ferri EF, Suarez Fernandez G, Dominguez Rodriguez L, Pozo Vegas M. Estudio serológico de perros procedentes de áreas urbanas y rurales en relación con la brucelosis. An Inst Nac Investig Agrar Ser Ganad 1982;17:
123-139.

5. Carmichael LE, Kenney RM. Canine abortion caused by Brucella canis. J Am Vet Med Assoc 1968;152:605-616.

6. Kim SG, Seo HJ, Kim ST, Jang YS, Jo MH. Serological and bacteriological study on canine brucellosis in the large kennel farms in Gyeongbuk province. Korean J Vet Serv 2010;33: 129-134.

7. Kang SI, Her M, Kim JW, Kim JY, Ko KY, Ha YM, Jung SC. Advanced multiplex PCR assay for differentiation of Brucella species. Appl Environ Microbiol 2011;77:6726-6728.

8. Xavier MN, Paixão TA, Poester FP, Lage AP, Santos RL. Pathological, immunohistochemical and bacteriological study of tissues and milk of cows and fetuses experimentally infected with Brucella abortus. J Comp Pathol 2009;140:149157.

9. Anderson JD, Smith H. The metabolism of erythritol by Brucella abortus. J Gen Microbiol 1965;38:109-124.

10. Hollett RB. Canine brucellosis: outbreaks and compliance. Theriogenology 2006;66:575-587.

11. Greene CE, Carmichael LE. Canine brucellosis. In: Greene CE (ed.). Infectious Diseases of the Dog and Cat. 4th ed. pp. 398-411, WB Saunders, Philadelphia, 2011.

12. Hofer E, Bag ZN, Revilla-Fern Ndez S, Melzer F, Tomaso H, L Pez-Go I I, Fasching G, Schmoll F. First detection of Brucella canis infections in a breeding kennel in Austria. New Microbiol 2012;35:507-510.

13. Keid LB, Soares RM, Vieira NR, Megid J, Salgado VR, Vasconcellos SA, da Costa M, Gregori F, Richtzenhain LJ. Diagnosis of canine brucellosis: comparison between serological and microbiological tests and a PCR based on primers to 16S-23S rDNA interspacer. Vet Res Commun 2007;31:951965. 